\title{
Comparison of mid-term outcomes of carotid artery stenting for moderate versus critical stenosis
}

Josef Veselka, Petra Zimolová, Lucie Martinkovičová, Pavol Tomašov, Petr Hájek, Martin Malý, Miloslav Špaček, David Zemánek, David Tesař

Cardiovascular Center, Department of Cardiology, University Hospital Motol, $2^{\text {nd }}$ Medical School, Charles University, Prague, Czech Republic

Submitted: 3 December 2010

Accepted: 31 March 2011

Arch Med Sci 2012; 8, 1: 75-80

DOI: 10.5114 /aoms.2012.27285

Copyright @ 2012 Termedia \& Banach

\section{Abstract}

Introduction: Little is known about the prognosis of moderate versus critical carotid stenosis treated by carotid artery stenting (CAS).

Material and methods: This was a retrospective analysis of a single-centre registry including 271 consecutive patients ( $69 \pm 9$ years, $87 \%$ at high risk for surgery), in whom 308 procedures were performed. The study included both symptomatic ( $\geq 50 \%$ carotid artery stenosis) and asymptomatic $(\geq 70 \%$ carotid artery stenosis) patients. The primary endpoint was the rate of adverse events during follow-up (range 1-48 months), defined as all-cause death or stroke.

Results: We treated 115 critical and 193 moderate stenoses and implanted 318 stents (56\% with closed cell design). Embolic protection systems were used in 296 cases (96\%). The technical success rate was $98.2 \%$ in the critical stenoses group and $99 \%$ in the moderate group (NS). During follow-up, the incidence of the primary endpoint was $12.9 \%$ (13 pts) in the critical stenoses group and $14.7 \%$ (25 pts) in the moderate stenoses group (estimated 3-year freedom from death/stroke was 0.844 vs. 0.812; log-rank test $p=0.983$ ). Left ventricular ejection fraction $<40 \%$, significant contralateral carotid artery occlusion or stenosis and renal insufficiency were identified as significant predictors of the primary endpoint $(p<0.03)$.

Conclusions: Carotid artery stenting with embolic protection systems in patients at high risk for carotid endarterectomy is safe. Patients with initially moderate and critical stenoses have an identical mid-term prognosis with regard to death and stroke.

Key words: carotid stenosis, stenting, follow-up.

\section{Introduction}

It appears that in patients with only moderate asymptomatic carotid artery stenosis (60-79\%), the risk of stroke is of the order of $2 \%$ per year or less if they are being treated medically. On the other hand, severe stenoses $(\geq 80 \%)$ are probably associated with an increased risk of stroke of $4-5 \%$ and warrant much more aggressive revascularization [1, 2]. Carotid artery stenting (CAS) is the method of choice for carotid artery revascularization mainly in patients at high risk for surgical endarterectomy [3-6]. However, outcomes of CAS are significantly influenced by anatomical considerations and a good post-procedural prognosis is at least partially determined by the selection of optimal patients who can maximally benefit from the chosen therapeutic alternative.

\author{
Corresponding author: \\ Josef Veselka MD, PhD, \\ FSCAI, FESC, FICA \\ Department of Cardiology \\ University Hospital Motol \\ $2^{\text {nd }}$ Medical School \\ Charles University \\ V úvalu 84 \\ Prague 5, 15000 \\ Czech Republic \\ E-mail: \\ veselka.josef@seznam.cz
}


Therefore, in this retrospective analysis of prospectively collected data in a single-centre registry, we evaluated the outcomes of CAS and compared the mid-term prognosis of consecutive highrisk patients with baseline moderate (50-89\%) vs. critical (90-99\%) stenosis.

\section{Material and methods}

Between September 2005 and October 2009, 271 consecutive patients ( $69 \pm 9$ years, $35 \%$ symptomatic, $87 \%$ at high risk for surgery) were enrolled, in whom 308 CAS procedures using different stents and distal embolic protective devices were performed.

\section{Patients}

The patients were divided into 2 groups according to the baseline degree of treated stenosis. Group
A comprised 170 patients with carotid stenosis ranging from 50\% to 89\%, while group B had 101 patients with carotid stenosis from $90 \%$ to $99 \%$ (Tables I-II). The study included both symptomatic ( $\geq 50 \%$ carotid artery stenosis) and asymptomatic $(\geq 70 \%$ carotid artery stenosis) patients. All the stenoses were quantified angiographically according to the NASCET criteria [7]. Stenoses were visually assessed and quantitated independently by two interventionalists. Quantitative analysis (Philips, Integris Allura, the Netherlands) was used only when visual assessment of individual lesions approximated $50 \%$ stenosis for symptomatic patients or $70 \%$ stenosis for asymptomatic patients, or when the assessment of both examiners was disparate in regard to categorization of lesion severity.

The criteria for high-risk patients included age $\geq 80$ years, history of open heart surgery, need

Table I. Patient characteristics

\begin{tabular}{|c|c|c|c|}
\hline Parameter & $\begin{array}{l}\text { Stenosis }<90 \% \\
\quad(n=170)\end{array}$ & $\begin{array}{l}\text { Stenosis } \geq 90 \% \\
\quad(n=101)\end{array}$ & Value of $p$ \\
\hline \multicolumn{4}{|l|}{ Age [years] } \\
\hline Mean \pm SD & $69 \pm 8$ & $68 \pm 10$ & 0.99 \\
\hline Range & $46-86$ & $49-89$ & \\
\hline Men & $56 \%$ & $65 \%$ & 0.16 \\
\hline Angina pectoris & $20 \%$ & $24 \%$ & 0.54 \\
\hline Dyspnoea, NYHA class > 1 & $34 \%$ & $36 \%$ & 0.79 \\
\hline Previous myocardial infarction & $37 \%$ & $25 \%$ & 0.04 \\
\hline Current smokers & $42 \%$ & $43 \%$ & 1.00 \\
\hline Hypertension & $89 \%$ & $91 \%$ & 0.67 \\
\hline Total plasma cholesterol [mmol/l; mg/dl] & $4.2 \pm 0.9 ; 162.5 \pm 34.8$ & $4.6 \pm 1.2 ; 178 \pm 46.4$ & 0.01 \\
\hline LDL cholesterol [mmol/l; mg/dl] & $2.4 \pm 0.8 ; 92.9 \pm 31$ & $2.7 \pm 0.9 ; 104.5 \pm 34.8$ & 0.03 \\
\hline HDL cholesterol [mmol/l; mg/dl] & $1.1 \pm 0.3 ; 42.6 \pm 11.6$ & $1.1 \pm 0.4 ; 42.6 \pm 15.5$ & 0.81 \\
\hline Plasma triglyceride $[\mathrm{mmol} / \mathrm{l} ; \mathrm{mg} / \mathrm{dl}]$ & $1.7 \pm 0.9 ; 148.8 \pm 78.8$ & $1.9 \pm 1.3 ; 166.3 \pm 113.8$ & 0.24 \\
\hline Diabetes mellitus & $38 \%$ & $48 \%$ & 0.13 \\
\hline Renal insufficiency & $20 \%$ & $23 \%$ & 0.64 \\
\hline Severe bronchopulmonary disease & $12 \%$ & $14 \%$ & 0.71 \\
\hline Peripheral arterial disease & $28 \%$ & $24 \%$ & 0.41 \\
\hline Left ventricular ejection fraction $<40 \%$ & $10 \%$ & $12 \%$ & 0.54 \\
\hline History of coronary artery bypass grafting & $19 \%$ & $15 \%$ & 0.51 \\
\hline Need of open heart surgery within 30 days & $9 \%$ & $15 \%$ & 0.16 \\
\hline Previous coronary artery intervention & $32 \%$ & $31 \%$ & 0.79 \\
\hline Known multivessel coronary artery disease & $42 \%$ & $34 \%$ & 0.19 \\
\hline Previous stroke & $36 \%$ & $39 \%$ & 0.80 \\
\hline $\begin{array}{l}\text { Cerebral ischaemic symptoms in the last month } \\
\text { (per procedure) }\end{array}$ & $15 \%$ & $29 \%$ & $<0.01$ \\
\hline $\begin{array}{l}\text { Cerebral ischaemic symptoms in the last } 6 \text { months } \\
\text { (per procedure) }\end{array}$ & $26 \%$ & $37 \%$ & 0.05 \\
\hline Patients with $\geq 1$ risk factors & $86 \%$ & $85 \%$ & 0.86 \\
\hline
\end{tabular}


for open heart surgery within 30 days, history of myocardial infarction, known coronary multivessel disease, left ventricular ejection fraction $\leq 40 \%$, severe bronchopulmonary disease, renal insufficiency, significant contralateral carotid disease and previous carotid endarterectomy. Additionally, patients were included if they had rejected surgical endarterectomy. All the patients provided their written informed consent prior to the procedure. Analysis was by intention to treat.

\section{Definitions}

Symptomatic patients had to have a history of ipsilateral stroke, transient ischaemic attack and/or amaurosis fugax within the last 6 months. Stroke was defined as a neurological deficit that persisted more than $24 \mathrm{~h}$. Minor stroke was defined as a new neurological deficit that resolved completely or returned to baseline within 30 days. Major adverse events (primary end-point) were non-fatal stroke or all-cause death.

\section{Interventions}

All the procedures were performed via the femoral approach using a 7- or an 8 Fr guiding catheter or a 6 Fr guiding sheath. The anticoagulant and antithrombotic protocol comprised administration of $200 \mathrm{mg}$ of aspirin and $300 \mathrm{mg}$ of clopidogrel at least $24 \mathrm{~h}$ prior to CAS [8]. A bolus of heparin (5,000-10,000 IU) was administered at the beginning of CAS to maintain an activation clotting time of 250-300 s. The type of stent as well as the type of embolic protection device was chosen at the discretion of the primary operator (J.V.). Our approach to CAS was performed as described elsewhere $[5,6]$. One of 3 filter devices was used: Filter Wire EZ (Boston Scientific, Mountain View, CA, USA), Angioguard (Cordis, Johnson and Johnson, Miami, FL, USA) or Defender (Medtronic, Minneapolis, MN, USA). Crotid artery stenting was performed using the following self-expanding stents: Precise RX (Cordis, Johnson and Johnson, Miami, FL, USA), Xact (Abbott Vascular, Galway, Ireland) Carotid Wallstent Monorail (Boston Scientific, Galway, Ireland), Sinus-Carotid-RX-System (Optimed, Ettlingen, Germany), NexStent (EndoTex Interventional Systems, Inc., Cupertino, CA, USA) and VascuFlex SEC (B.Braun, Melsungen, Germany).

All the patients were repeatedly examined by nursing staff and physicians (including neurological examination) and all symptomatic patients were examined by board-certified neurologists. Contrastinduced nephropathy prevention was performed if needed [9]. Post-procedural intracranial examination with magnetic resonance imaging (MRI) or computed tomography (CT) was performed if the neurological status of the patient changed. Asymp-
Table II. Medication prior to stenting

\begin{tabular}{|lccc|}
\hline & $\begin{array}{c}\text { Stenosis }<90 \% \\
(n=170)\end{array}$ & $\begin{array}{c}\text { Stenosis } \geq 90 \% \\
(n=101)\end{array}$ & Value of $p$ \\
\hline Statin & $81 \%$ & $71 \%$ & 0.09 \\
\hline ACE inhibitor & $65 \%$ & $66 \%$ & 1.00 \\
\hline$\beta$-Blocker & $64 \%$ & $61 \%$ & 0.79 \\
\hline
\end{tabular}

tomatic patients were discharged on the following day. All the patients were asked to undergo clinical 30-day, 6-month, 1-year, and 2-year follow-ups. To assess further clinical outcomes, all the patients were contacted via telephone or mail. All adverse events were confirmed by reviewing the medical records and the national database of the departed.

\section{Statistical analysis}

Continuous variables are expressed as mean \pm $\mathrm{SD}$, discrete variables as counts and/or percentages. Fisher's exact test and t-test or Mann-Whitney $U$ test were used to explore categorical and continuous baseline characteristics between groups. Kaplan-Meier estimates were used to construct stroke and death, and stroke-free survival curves. These curves were compared between procedures for moderate vs. critical stenoses using a log-rank test. Analyses covered multiple-record data and their variation over time. A backward stepwise multiple Cox regression model was performed to identify predictors of the primary endpoint. The variables included in the Cox regression analysis were as follows: age, gender, diabetes, smoking, hypertension, peripheral artery disease, severe bronchopulmonary disease, renal insufficiency (plasma creatinine $>130 \mu \mathrm{mol} / \mathrm{l}$ ), history of percutaneous coronary intervention, history of coronary artery bypass grafting, need of open heart surgery in the following 30 days, angina pectoris > class 1 CCS, history of myocardial infarction at any time, left ventricular ejection fraction $<40 \%$, history of stroke, cerebral ischaemic symptoms in the last 6 months, cerebral ischaemic symptoms in the last 1 month, initial carotid artery stenosis, residual carotid artery stenosis, contralateral carotid artery occlusion, significant contralateral carotid artery stenosis ( $>50 \%$ ) or occlusion, total cholesterol level, HDL cholesterol level, LDL cholesterol level, triglyceride, aspirin pre-treatment, clopidogrel pre-treatment, statin pre-treatment, direct carotid stenting and fluoroscopic time. A $p$ value less than 0.05 was considered statistically significant. We used the statistical software Stata, release 9.2. (StataCorp LP, College Station, TX, USA).

\section{Results}

In a total of 271 consecutive patients ( $69 \pm 9$ years, $35 \%$ symptomatic, $87 \%$ at high risk for surgery), we treated 308 significantly stenosed carotid arteries 
(193 moderate and 115 critical stenoses) and implanted 318 stents (56\% with closed cell design) (Table III). In 9 patients (3\%), a bilateral carotid artery disease was treated by CAS during a single procedure. We performed 60 repeated procedures $(19 \%)$ because of bilateral stenosis (45 procedures, $15 \%$ ) or post-CAS re-stenosis (15 procedures, $5 \%$ ). The technical success rate of CAS (residual stenosis $\leq 30 \%$ ) was $98.7 \%$; we did not succeed in 2 cases in each group (99\% vs. $98 \%$; NS). Direct carotid stent implantation without previous pre-dilation was performed significantly more often in group A patients ( $93 \%$ vs. $78 \% ; p<0.01)$.

In the hospital, postprocedural strokes occurred in 5 patients ( 3 and 2 strokes in groups A and B, respectively) and the 2 patients in group $B$ expired. Of the 2 deaths, one was due to myocardial infarction and subsequent heart failure, and one to pneumonia. There were no periprocedural intracranial haemorrhages or periprocedural myocardial infarctions. No further complications occurred. All the patients were examined 30 days after the procedure.

Between the hospital discharge and 30-day examination, a further 2 strokes occurred (1 in each group) and one of these patients (group B) subsequently expired. One patient (group B) with a severe left ventricular dysfunction and coronary triple vessel disease died suddenly after hospital discharge. Overall, stroke or neurological death occurred in 7 patients (2.6\%) during the 30-day follow-up. The total hierarchical occurrence of 30-day all-cause death or stroke or myocardial infarction was $3.7 \%(2.4 \%$ vs. $6 \% ; p=0.24)$.
No patients were lost from the follow-up. The median follow-up period was 12.1 months (1-47) and 11.3 months (1-48) for groups $A$ and $B$, respectively $(p=0.03)$. Clinical follow-up for $\geq 12$ months was available in $52 \%$ of the patients. No other non-fatal strokes occurred during the follow-up for $\geq 30$ days. Overall, the incidence of the primary endpoint was $14.7 \%$ (25 pts) and $12.9 \%$ (13 pts) in groups $A$ and $B$, respectively (estimated 3-year freedom from death/stroke was 0.812 vs. 0.844 ; log-rank test $p=0.983)$. The outcomes are summarized in Figures 1 and 2.

A backward stepwise multiple Cox regression model identified left ventricular ejection fraction $<40 \%$, significant contralateral carotid artery stenosis/occlusion and renal insufficiency as significant predictors of the primary endpoint (Table IV).

\section{Discussion}

In this study, we compared the mid-term outcomes of patients treated by CAS with special attention to the baseline severity of carotid artery stenosis. These results suggest that CAS with embolic protection systems is effective and safe. Patients with initially both moderate (50-89\%) and critical stenoses (90-99\%) had an identical mid-term prognosis with regard to death and stroke. In this population, a backward stepwise multiple Cox regression model identified left ventricular ejection fraction $<40 \%$, significant contralateral carotid artery stenosis/occlusion and renal insufficiency as significant predictors of the occurrence of all-cause death or stroke.

Table III. Interventional and angiographic characteristics of the study population

\begin{tabular}{|lccc|}
\hline Variable & $\begin{array}{c}\text { Stenosis }<90 \% \\
(n=193 \text { procedures })\end{array}$ & $\begin{array}{c}\text { Stenosis } \geq 90 \% \\
(n=115 \text { procedures })\end{array}$ & Value of $p$ \\
\hline Lesion located in LICA/RICA & $50 \% / 50 \%$ & $43 \% / 57 \%$ & 0.29 \\
\hline Ostial ICA lesion & $77 \%$ & $74 \%$ & 0.67 \\
\hline Tandem ICA lesion & $21 \%$ & $26 \%$ & 0.33 \\
\hline Restenosis after endarterectomy & $4 \%$ & $7 \%$ & 0.30 \\
\hline In-stent restenosis & $5.7 \%$ & $6.1 \%$ & 1.00 \\
\hline Stenosis at baseline & $75.1 \pm 6.8$ & $92.6 \pm 3.5$ & $<0.01$ \\
\hline Residual stenosis & $9.3 \pm 10.2$ & $10.5 \pm 14.3$ & 0.92 \\
\hline Contralateral occlusion & $11 \%$ & $9 \%$ & 0.70 \\
\hline Contralateral stenosis $>50 \%$ & $37 \%$ & $40 \%$ & 0.63 \\
\hline Contrast medium [ml] & $135 \pm 43$ & $137 \pm 49$ & 0.85 \\
\hline Direct stenting & $93 \%$ & $78 \%$ & $<0.01$ \\
\hline Mean stent length [mm] & $36 \pm 11$ & $39 \pm 13$ & 0.02 \\
\hline Atropine during procedure & $53 \%$ & $53 \%$ & 1.00 \\
\hline Number of post-dilations & $1.1 \pm 0.8$ & $1.1 \pm 0.8$ & 0.71 \\
\hline Fluoroscopic time, median/range [min] & $6.0 / 2.5-25.7$ & $6.2 / 2.9-31.5$ & 0.03 \\
\hline
\end{tabular}




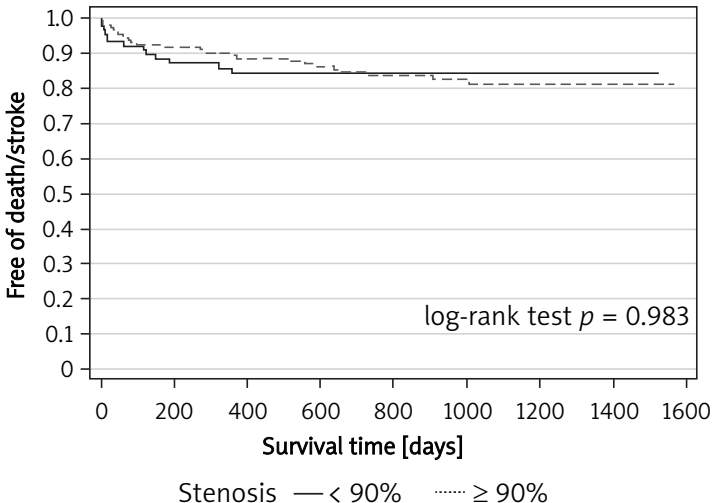

Figure 1. Kaplan-Meier curves for freedom from death or stroke

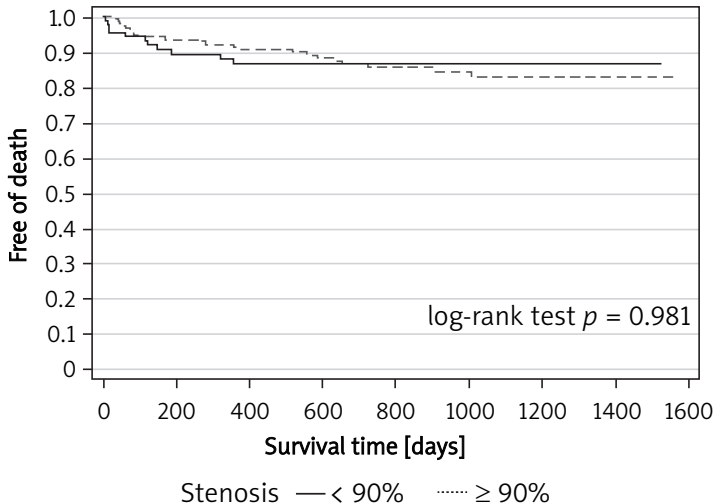

Figure 2. Kaplan-Meier curves for freedom from death

Table IV. Significant predictors of the occurrence of the primary endpoint (all-cause death or stroke)

\begin{tabular}{|lccc|}
\hline Variable & Hazard ratio & 95\% confidence interval & Value of $p$ \\
\hline Left ventricular ejection fraction $<40 \%$ & 3.34 & $1.41-7.88$ & 0.006 \\
\hline Contralateral carotid artery stenosis or occlusion & 3.36 & $1.28-8.78$ & 0.014 \\
\hline Renal insufficiency & 2.56 & $1.14-5.77$ & 0.023 \\
\hline
\end{tabular}

We assume our findings might be interesting and add to the medical literature. First, the present study comprised a population of consecutive and mostly high-risk patients with significant carotid artery disease in which one third had stenosis $\geq 90 \%$. It seems likely that this study presents our "real world" clinical practice in which the vast majority of patients can be treated by CAS with acceptable mid-term outcomes. It is notable that according to multivariable analysis, the symptomatic status prior to intervention was not an independent predictor of mid-term prognosis. Second, as was demonstrated in the past, patients with stenosis $>80-90 \%$ have a higher risk of future stroke [1, 2]. Moreover, in this study, patients with critical stenoses were more often symptomatic prior to CAS. However, this study suggests that mid-term outcomes of patients with baseline critical or moderate stenoses are identical after a successful CAS. Therefore, we can hypothesize that the treatment of critical carotid stenoses is, in comparison with moderate stenoses, more beneficial with the maintenance of acceptable safety. Similarly, a subgroup analysis of the North American Symptomatic Carotid Endarterectomy Trial (NASCET) demonstrated the greatest benefit of endarterectomy during long-term followup in patients with more severe carotid disease (stenosis 90-99\%) [10]. Third, in this study, all the strokes occurred in the first postprocedural month. Thus, the probability of late postprocedural stroke seems to be very low in this mainly asymptomatic population, which was published previously [1, 2]. In the current era we should focus especially on the appropriate patient selection and fine-tuning of CAS technique [11, 12]. Interestingly, the preferable catheterization technique in this study was direct stent implantation and this approach was successful in more than $80 \%$ of the cases with critical carotid artery stenosis. Fourth, the results of the multiple regression analysis suggest that the occurrence of all-cause death or stroke was determined both by generally known risk factors (left ventricular dysfunction and renal insufficiency) and by the extent of carotid artery disease (significant contralateral stenosis or occlusion).

Several interventional groups have attempted to show the benefit of protective embolic devices in reduction of periprocedural embolism [13]. Although no randomized data are available, we feel that closed cell designed stents, direct stent implantation without previous dilation and use of appropriate protective embolic devices are the most important factors improving the early postprocedural outcome of treated patients $[5,6]$. Furthermore, the proper selection of patients including a thorough assessment of the overall clinical risk also plays an important role in the indication of CAS. Therefore, we should bear in mind the possible predictors of the mid-term adverse events as were suggested in this study.

This single-centre study must be understood in the context of its limitations. All the procedures were performed by a single cath-lab team with long-term experience with CAS. This fact seems to be important mainly in the light of the recent discussion of the three randomized studies compar- 
ing CAS and carotid endarterectomy that are criticized by many interventionalists because of the insufficient endovascular experience of operators participating in the trials [14-17]. In contrast to those studies, a recently published CREST study [18] with similar results of CAS and carotid endarterectomy had a lead-in phase to train less experienced operators prior to the trial. Hence, the present results again underline the essential role of appropriate physician training and credentialing [19-22].

In conclusion, CAS with embolic protection systems in patients at high risk for carotid endarterectomy is safe. Patients with initially both moderate (50-89\%) and critical stenoses (90-99\%) treated by CAS had an identical mid-term prognosis with regard to death and stroke.

\section{Acknowledgements}

The authors thank Eva Hansvenclova for her assistance in the data collection and registry analysis. The study was supported by grant No. 00064203 from the Ministry of Health of the Czech Republic.

\section{References}

1. Chambers BR, Norris JW. Outcome in patients with asymptomatic neck bruits. N Engl J Med 2003; 315: 860-5.

2. Randomized trial of endarterectomy for recently symptomatic carotid stenosis: final results of the MRC European Carotid Surgery Trial (ECST). Lancet 1998; 351: 1379-87.

3. Al-Mubarak N, Roubin GS, Vitek JJ, New G, lyer SS. Procedural safety and short-term outcome of ambulatory carotid stenting. Stroke 2001; 32: 2305-9.

4. Bates ER, Babb JD, Casey DE, et al. ACCF/SCAI/SVMB/SIR/ ASITN 2007 clinical expert consensus document on carotid stenting: a report of the American College of Cardiology Foundation Task Force on Clinical Expert Consensus Documents (ACCF/SCAI/SVMB/SIR/ASITN Clinical Expert Consensus Document Committee on Carotid Stenting). J Am Coll Cardiol 2007; 49: 126-70.

5. Veselka J, Černá D, Zimolová P, et al. Thirty-day outcomes of direct carotid artery stenting with cerebral protection in high-risk patients. Circ J 2007; 71: 1468-72.

6. Veselka J, Černá D, Zimolová P, et al. Feasibility, safety, and early outcomes of direct carotid artery stent implantation with use of the FilterWire EZ Embolic Protection System. Catheter Cardiovasc Interv 2009; 73: 733-8.

7. U-King-Im JM, Trivedi RA, Cross JJ, et al. Measuring carotid stenosis on contrast-enhanced magnetic resonance angiography: diagnostic performance and reproducibility of 3 different methods. Stroke 2004; 35: 2083-8.

8. Catakoglu AB, Aytekin S, Celebi H, et al. The influence of aspirin resistance on non-fatal coronary events following percutaneous coronary interventions. Arch Med Sci 2009; 5: 531-8.

9. Uyarel H, Cam N, Ergelen M, et al. Contrast-induced nephropathy in patients undergoing primary angioplasty for acute myocardial infarction: incidence, a simple risk score, and prognosis. Arch Med Sci 2009; 5: 550-8.
10. North American Symptomatic Carotid Endarterectomy Trial Collaborators. Beneficial effect of carotid endarterectomy in symptomatic patients with high-grade carotid stenosis. N Engl J Med 1991; 325: 445-53.

11. Roubin GS, lyer S, Halkin A, Vitek JJ, Brennan C. Realizing the potential of carotid artery stenting: proposed paradigms for patient selection and procedural technique. Circulation 2006; 113: 2021-30.

12. MacDonald S, Evans DH, Griffiths PD, et al. Filter-protected versus unprotected carotid artery stenting: a randomised trial. Cerebrovasc Dis 2006; 29: 282-9.

13. Jansen O, Fiehler J, Hartmann M, Bruckmann H. Protection or nonprotection in carotid stent angioplasty: the influence of interventional techniques on outcome data from the SPACE Trial. Stroke 2009; 40: 841-6.

14. Roffi M, Sievert H, Gray WA, et al. Carotid artery stenting versus surgery: adequate comparisons? Lancet Neurol 2010; 9: 339-41.

15. SPACE Collaborative Group. 30 day results from the SPACE trial of stent-protected angioplasty versus carotid endarterectomy in symptomatic patients: a randomised non-inferiority trial. Lancet 2006; 368: 1239-47.

16. Mas JL, Chatellier G, Beyssen B, et al. Endarterectomy versus stenting in patients with symptomatic severe carotid stenosis. N Engl J Med 2006; 355: 1660-71.

17. International Carotid Stenting Study investigators, Ederle J, Dobson J, Featherstone RL, et al. Carotid artery stenting compared with endarterectomy in patients with symptomatic carotid stenosis (International Carotid Stenting Study): an interim analysis of a randomised controlled trial. Lancet 2010; 375: 985-97.

18. Brott TG, Hobson RW 2nd, Howard G, et al.; CREST Investigators. Stenting versus endarterectomy for treatment of carotid-artery stenosis. N Engl J Med 2010; 363: 11-23.

19. Verzini F, Cao P, De Rango P, et al. Appropriateness of learning curve for carotid artery stenting: an analysis of periprocedural complications. J Vasc Surg 2006; 44: 1205-11.

20. Anderson HV, Rosenfield KA, White CJ, et al. Clinical features and outcomes of carotid artery stenting by clinical expert consensus criteria: a report from the CARE registry. Catheter Cardiovasc Interv 2010; 75: 519-25.

21. Uflacker J. How to optimize carotid artery stenting. J Cardiovasc Surg 2007; 48: 131-49.

22. Karkos CD, Karamanos DG, Papazoglou KO, Demiropoulos FP, Papadimitriou DN, Gerassimidis TS. Thirty-day outcome following carotid artery stenting: a 10 year experience from a single center. Cardiovasc Intervent Radiol 2010; 33: 34-40. 